\title{
YERBILIMLERI
}

Bulletin for Earth Sciences

Yerbilimleri, 2021, 42 (1), 70-84, DOI: 10.17824/yerbilimleri.774533

Hacettepe Üniversitesi Yerbilimleri Uygulama ve Araştırma Merkezi Bülteni

Bulletin of the Earth Sciences Application and Research Centre of Hacettepe University

\section{Silt türü bir Zeminin Gerilme Rahatlaması üzerine Deneysel bir Çalışma}

An Experimental Study on Stress Relaxation of a Silt-type Soil

\author{
Eren KÖMÜRLÜ ${ }^{1 *}$ \\ ${ }^{1}$ Giresun Üniversitesi, İnşaat Mühendisliği Bölümü, Giresun
}

Geliş (received): 27 Temmuz (July) 2020 Kabul (accepted): 14 Nisan (April) 2021

\section{ÖZ}

Bu çalışmada, farklı birim deformasyon seviyelerine tabi tutulan silt türü zemin numuneleri üzerine gerilme rahatlaması testleri gerçekleştirilmiştir. Gerilme değerlerinin zamana bağlı değişimleri ile farklı birim deformasyon değerlerinin gerilme rahatlaması üzerine etkileri incelenmiştir. Ayrıca, gerilme rahatlamasının tek eksenli sıkışma dayanımı (serbest basınç mukavemeti) değerleri üzerindeki etkileri bir dizi deneysel çalışma ile belirlenmiştir. Elde edilen bulgular, gerilme rahatlamasının tek eksenli sıkışma dayanımı (TESD) değerleri üzerinde önemli etkisi olduğunu göstermektedir. TESD değerleri belirli bir seviyeye kadar gerilme rahatlaması yaşanan birim deformasyon miktarı arttıkça yükselmiştir. Ancak, dayanım değerlerine yakın yüksek gerilme seviyelerinde başlayan rahatlamaların TESD değerlerini olumsuz etkilediği görülmüştür.

Anahtar kelimeler: Gerilme rahatlaması, zamana bağlı davranış, siltlerin sıkışma dayanımı, gerilme düşüşü.

https://doi.org/10.17824/yerbilimleri.774533

E. KÖMÜRLÜ ekomurlu@giresun.edu.tr

Giresun Üniversitesi, Inşaat Mühendisliği Bölümü, Giresun ORCID 0000-0002-2123-7678 


\section{Abstract}

In this study, stress relaxation tests were carried out by keeping specimens of a silt type soil under different strain levels. Decreases in the stress values with time data was collected to better understand the effect of the strain level on the relaxation properties of soil specimens. In addition, the stress relaxation effect on the uniaxial compressive strength (UCS) values of the specimens was investigated with a series of tests. According to the results obtained from this study, the UCS values of the silt specimens significantly vary as a result of the stress relaxation effect. The UCS values were determined to increase with an increase of relaxation strain level to a threshold value. On the other hand, the UCS values were found to be affected adversely in case of high stress levels at the initiation of the relaxation, which are close to the peak level.

Keywords: Stress relaxation, time-dependent effect, compressive strength of silts, stress drop.

\section{Giriş}

Gerilme rahatlaması sabit birim deformasyon altında zamana bağlı gerilme değerlerindeki azalma olarak tanımlanmaktadır. Zeminlerin mekanik özellikleri zaman faktörüne bağlı değişim sergilemektedir. Sabit gerilme altında zamana bağlı birim deformasyon değerlerindeki değişim olan sünme konusunda zeminler için literatürde çok sayıda çalışma bulmak mümkündür (Dob et al., 2016; Tran et al., 2018; Sabir et al., 2016; Wang et al., 2014; Kwok and Bolton, 2013). Ancak, zeminlerde gerilme rahatlaması sünmeye kıyasla daha az çalışılmış bir konudur. Zeminler sabit birim deformasyon altında bekletilmeleri durumunda taneli yapıda malzeme olmaları ve zamanla tane temas yüzeylerinde plastik deformasyon oluşması sebebiyle dışardan etkiyen gerilme değerlerinde önemli ölçüde azalma gösterebilmektedir (Lade et al., 2010; Yin et al., 2014; Staszewska and Cudny, 2020).

Tane boyutu, tane şekli, su içeriği, ikinci ve üçüncü eksenlerden çevresel basınç gibi çeşitli parametrelerin gerilme rahatlaması süresi ve oranı üzerinde etkili olduğu ilgili çalışmalar ile belirlenmiştir (Sanchez-Giron et al., 2001; Lade and Karimpour, 2015; Kutergin et al., 2013; Levin et al., 2019). Gerilme rahatlaması zamana bağlı plastik deformasyonun başlaması sonucu oluşmaktadır. Kısa süreli yüklemelerde elastik deformasyon yaşanan bir gerilme seviyesinde dahi birim deformasyonun 
sabitlenmesi ile zamanla plastik deformasyonlar gözlemlenmekte ve gerilme rahatlaması miktarına bağlı olarak eski boya dönebilme özelliğinde kayıplar olmaktadır. Sabit birim deformasyonda gerilme rahatlaması olurken dışarıdan etkiyen gerilme değerlerindeki azalma hızı ilk etapta nispeten yüksektir ve ilerleyen aşamalarda azalış göstermektedir. Gerilme rahatlamasının tamamlanmış olduğu süreden sonra eski boya dönme eğilimi tamamı ile kaybedilmiştir. Bir diğer ifadeyle, gerilme rahatlamasını tamamlamış ve gerilme değerleri sıfırlanmış olan bir zemin numunesi yükleme sonrası boyunu koruyacak ve gerilme rahatlamasının gerçekleşmiş olduğu birim deformasyonda kalacaktır (Kamao, 2016; Liingaard et al., 2004).

$\mathrm{Bu}$ çalışmada farklı birim deformasyon seviyelerinde silt türü bir zeminin gerilme rahatlaması özellikleri incelenmiş ve farklı oranlarda gerilme rahatlaması yaşanması durumunun tek eksenli sıkışma dayanımı (serbest basınç mukavemeti) değerleri üzerindeki etkileri bir dizi deneysel çalışma ile incelenmiştir. Çoğu zaman mühendislik tasarım ve analizlerinde göz ardı edilen gerilme rahatlaması konusunun zeminlerin dayanım degerleri üzerindeki etkisinin belirlenmesi hususunda bu çalışmanın fayda sağlaması amaçlanmıştır. Farklı birim deformasyon seviyeleri ve bekleme süreleri için gerilme değerlerinde ne ölçüde azalma olduğu belirlenmiş ve gerilme rahatlaması yaşanması durumunun silt türü bir zeminin dayanım değerleri üzerindeki etkileri incelenmiştir.

\section{MALZEME VE METOT}

\section{Zemin sınıflandırması}

Bu çalışmada, Ordu ili Gülyalı ilçesi Turnasuyu mevkiinden alınan ve 297 mikrometre altı (50 nolu elek) tane boyuna sahip elenmiş zemin kullanılmıştır. Ayrıca deneylerde kullanılan bu malzemenin kütlece \%62'lik kısmının da 88 mikrometre (170 nolu elek) altı olduğu belirlenmiştir. Sınıflandırma için bu malzeme üzerine Atterberg kıvam limitleri deneyleri gerçekleştirilmiştir. Plastik limit ve Casagrande likit limit deneyi ASTM D3418-10 kodlu Amerikan standardında belirtilen metodolojiye uygun olarak yapılmıştır. Numuneler standart Casagrande kasesi üzerine yerleştirilerek standart yarık açma bıçağı ile kesilmiş ve kase üzerinde ikiye bölünmüştür. Kase otomatik motor yardımı ile tekrarlı olarak düşmüş ve 25 vuruşa denk gelen yarıkta kapanmanın 
yaşandığı su içeriği likit limit değeri olarak belirlenmiştir (ASTM International, 2010). Su içeriği su kütlesinin kuru (katı) kütleye oranı olarak hesaplanmıştır. Plastik limit ve likit limit değerlerinin belirlenmesi için numuneler $105{ }^{\circ} \mathrm{C}$ derecede 1 gün süre ile etüvde bekletilerek kurutulmuştur. Plastik limit deneyi için yaygın olarak uygulanmakta olan cam plaka üzerinde çubuk yuvarlama deneyi yapılmıştır. Çubuk numunelerin çapları 3 mm'ye düştüğünde yüzeyinde çatlama gösterdiği su içeriği olarak plastik limit değerleri ASTM D3418-10 standardına uygun biçimde bulunmuştur (Şekil 1 ve Şekil 2).

\section{Gerilme Rahatlaması ve Tek Eksenli Sıkışma Dayanımı Deneyleri}

Zemin numunesi araziden getirildikten sonra tane yüzey neminin kısmen alınması için bir süre etüve konmuş ve eleme öncesi tanelerin iyi ayrışması için zemin düz yüzeyli bir taş kullanılarak darbe ile ezilmiştir. Tanelerin ayrışması deneyde kullanılan elek altı malzeme miktarını artırmak için amaçlanmıştır. Elenmiş zemin yaklaşık iki gün oda sıcaklığı koşulunda laboratuvarda beklemiş ve bir miktar hava nemini almıştır. Zemin bir leğen içerisinde, kütlesinin \%8 kadarı su eklenerek elle karıştırılmış, homojenizasyonu sağlanmış ve ardından iç çapı $46 \mathrm{~mm}$ olan plastik silindirik kalıplar içerisine yerleştirilmiştir (Şekil 3). Kalıplama öncesi bir miktar su eklemenin amacı kalıp şeklinin daha iyi korunabilmesidir. Çok kuru bir zeminin kalıptan çıkarılırken dağılabileceği öngörülmüştür. Zemin 3 kademeli olarak kalıba doldurulmuş, her kademeden sonra numune 25 vuruş tokmakla sıkıştırılmıştır.

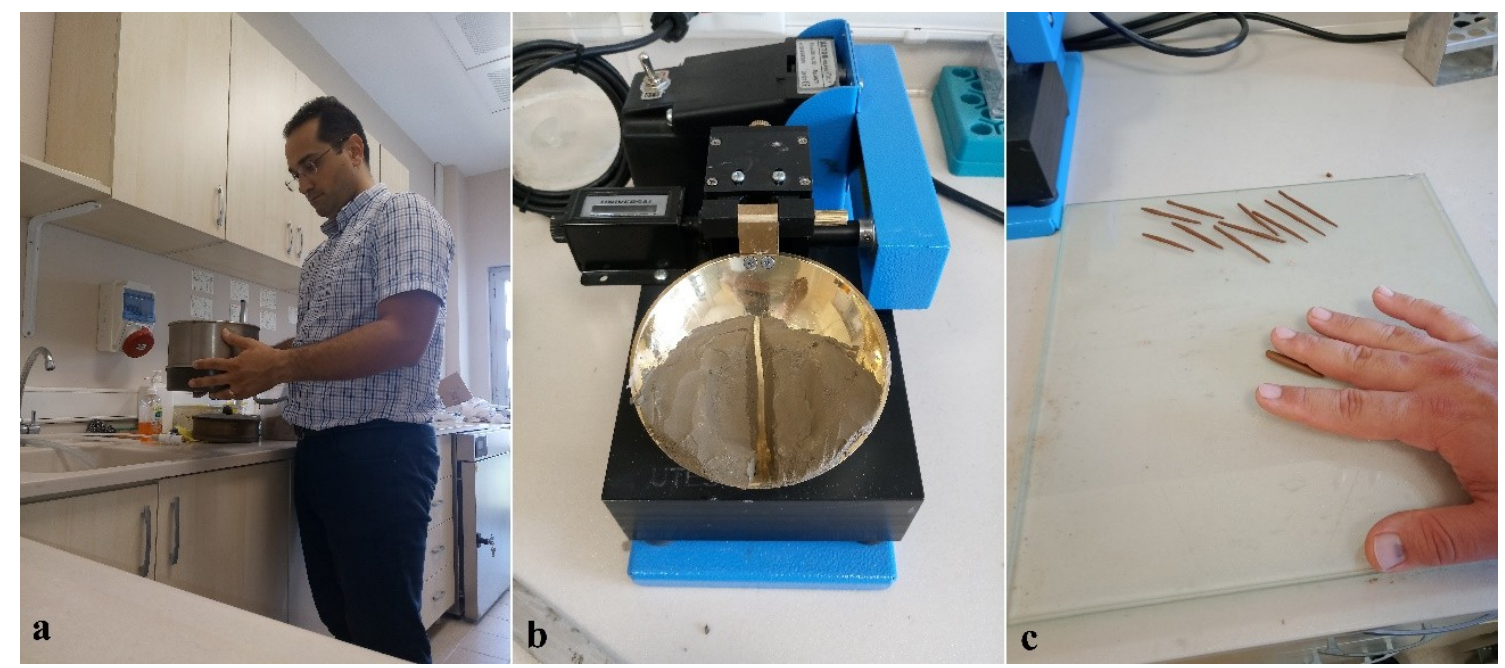

Şekil 1. a) Numune eleme, b) likit limit testi, c) plastik limit testi.

Figure 1. a) Sample sieving, b) liquid limit test, c) plastic limit test. 


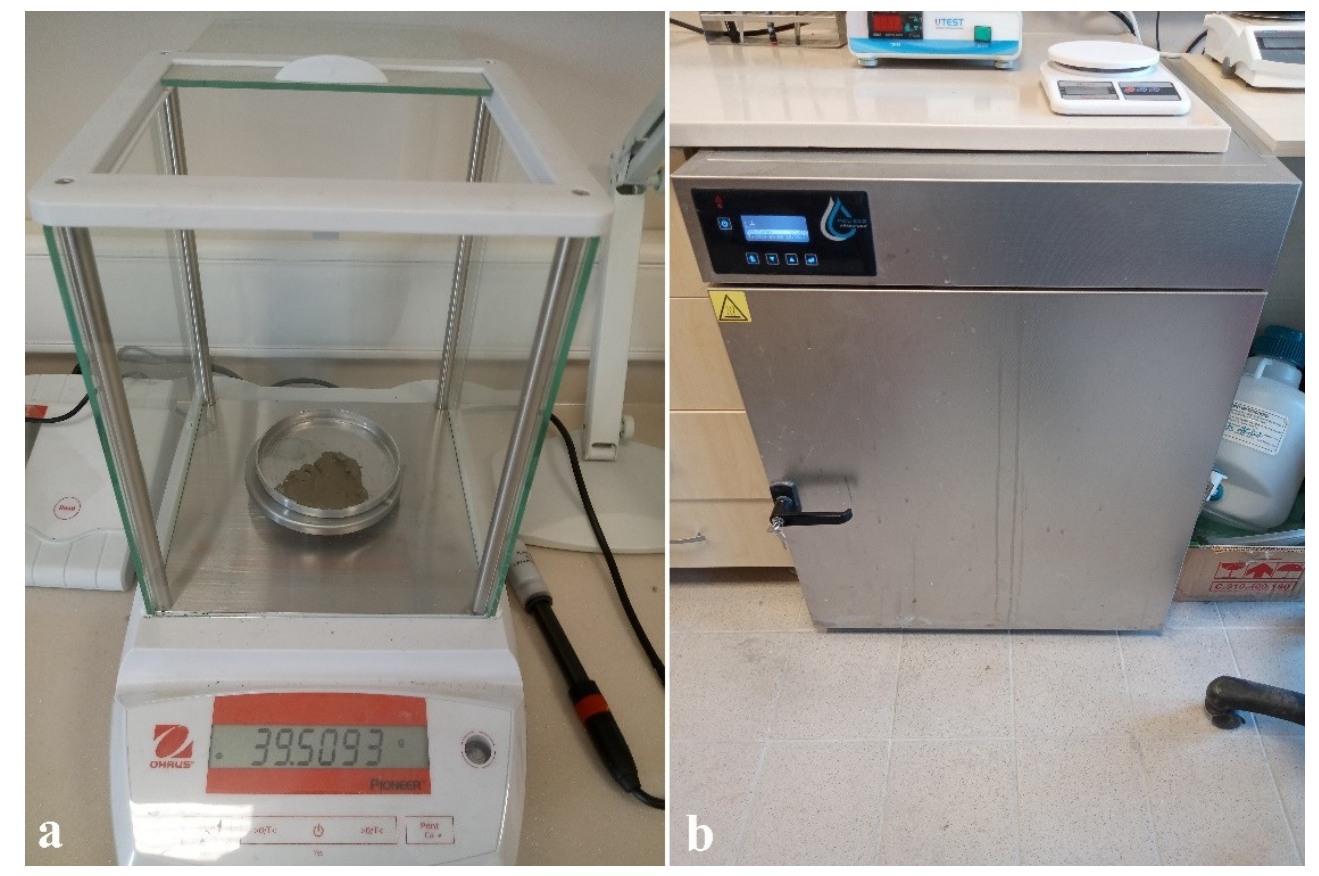

Şekil 2. Kıvam limiti deneylerinde kullanılan hassas terazi (a) ve etüv (b).

Figure 2. Precision scales (a) and the stove (b) used in the Atterberg limits tests.

Boy/çap oranı 2 olan numuneler bir gün oda sıcaklığında laboratuvarda beklemiş ve tek eksenli sıkışma dayanımı (serbest basınç mukavemeti) deneyi öncesi kalıptan çıkarılmıştır. Test edilen tüm numunelerin kalıplama prosedürü tamamı ile aynıdır. Kalıp olarak uzunluğu boyunca kesilmiş (yarıklı) $2 \mathrm{~mm}$ et kalınlığına sahip plastik boru kullanılmıştır. Numuneler yarık açılarak kalıplarından rahatlıkla çıkarılmıştır. Tek eksenli sıkışma dayanımı deneyinde yükleme hızı $0.5 \mathrm{~mm} /$ dak olarak seçilmiştir. Numunelerin yükleme platenleri ile temas edecek üst yüzeylerindeki pürüzler falçata ile hafifçe alınmış, yüzeyler mümkün olduğunca düzleştirilmistir. Ayrıca, kalıp içindeyken de numune üst yüzeyi hafif tokmaklanarak düzeltilmiştir. 


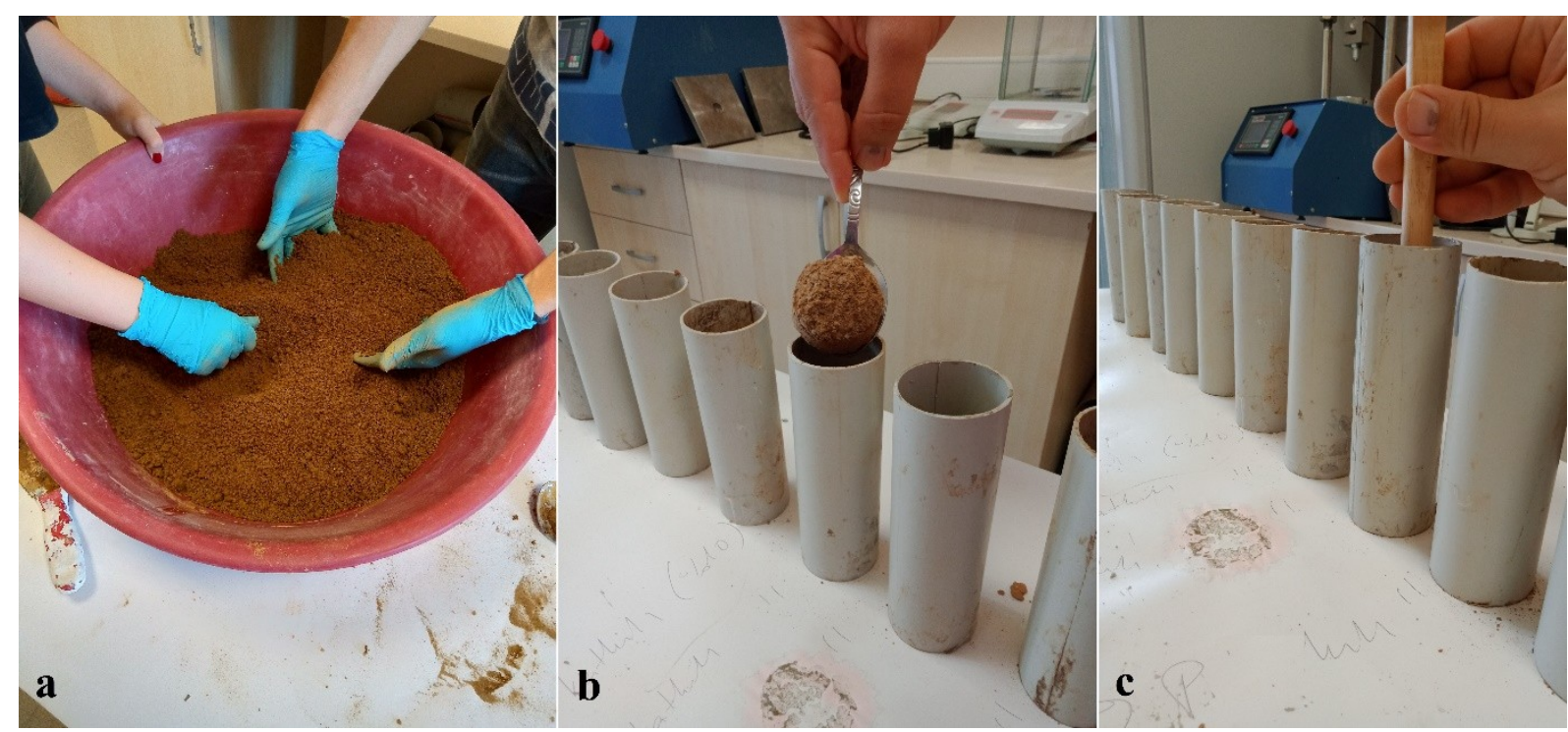

Şekil 3. a) Numune karıştırma, b) kalıba doldurma, c) tokmaklama.

Figure 3. a) Soil mixing, b) filling in moulds, c) compaction by mallet.

Bu çalışma kapsamında toplam 16 adet numune kullanılmıştır. Numunelerin bir bölümü gerilme rahatlaması yaşamadan tek eksenli sıkışma dayanımı deneyinde kullanılmıştır. Diğer bölümü ise farklı birim deformasyon seviyelerine kadar yüklenmiş ve yükleme durdurularak sabit birim deformasyonlar altında bekletilmiştir. Yüklemenin durdurulduğu farklı birim deformasyon değerleri için zamana bağlı yük değişimleri okunmuştur. Gerilme rahatlaması olan numunelerde yük değerleri sıfırlanana kadar beklenmesini takiben tek eksenli sıkışma dayanımı deneyleri gerçekleştirilmiştir. Bu yolla gerilme rahatlaması olan ve olmayan numunelerin dayanım değerleri kıyaslamalı olarak incelenebilmiştir. Tek eksenli dayanım testi ve gerilme rahatlaması sürecindeki yük değerlerinin ölçülmesi için $50 \mathrm{kN}$ kapasiteli hassas elektrik motorlu bir pres kullanılmıştır (Şekil 4). Test edilen numunelerin benzer boşluk oranına sahip olduğunun sınanması için numunelerin boyları hassas olarak ölçülmüş ve 0,001 gr hassası̆ı̆ında elektronik terazi ile tartılarak yoğunluk değerleri belirlenmiş̧ir. Bu işlem numunelerin kalıplarından çıkarılmasını takiben gerçekleştirilmiştir. 


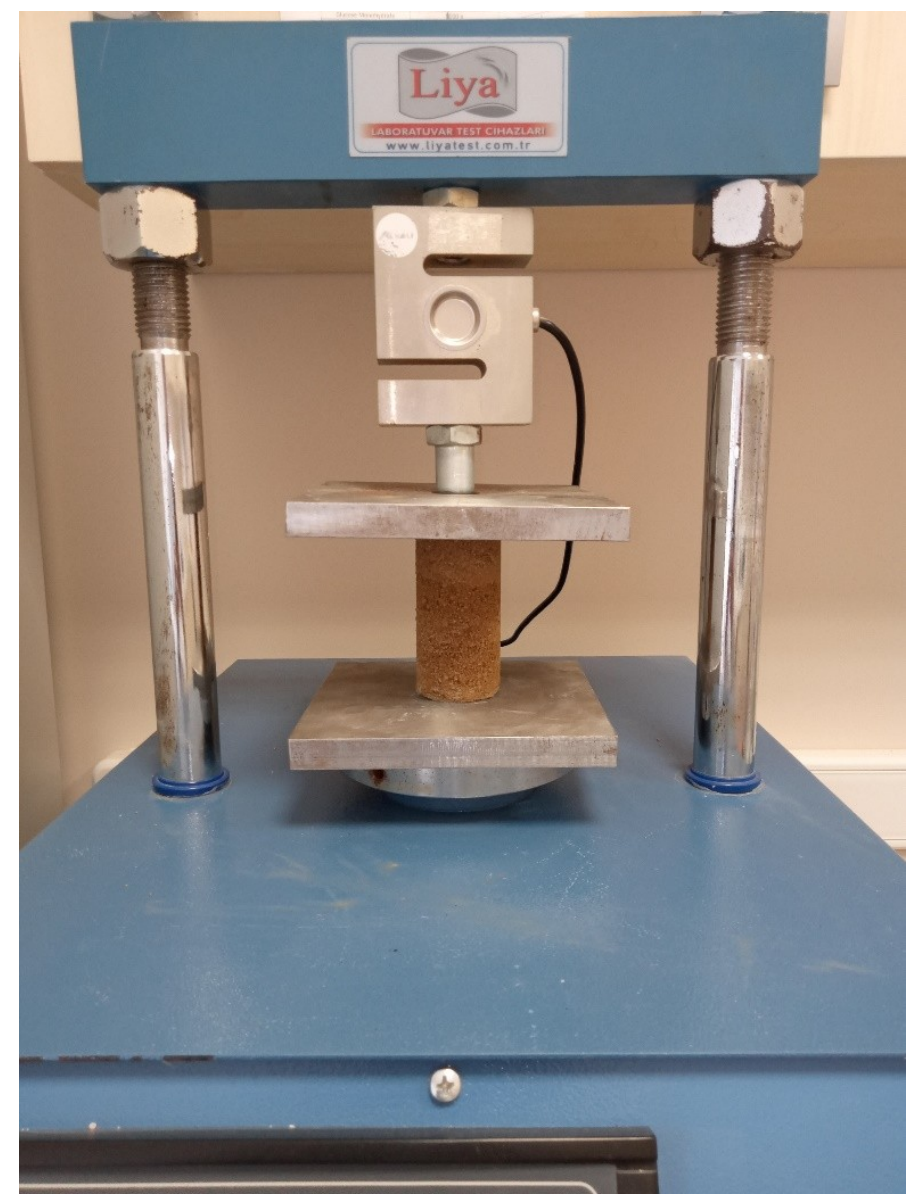

Şekil 4. Tek eksenli sıkışma dayanımı (serbest basınç mukavemeti) deneyi.

Figure 4. Uniaxial compressive strength test (unconfined compression test).

\section{BULGULAR}

Casagrande likit limit deneyinden elde edilen bulgular Şekil 5a'da verilmiştir. Plastik limit değeri \%27,1 olarak belirlenen zemin Şekil 5b'de verilen Casagrande zemin sınıflama kartına göre ML kodlu inorganic silt olarak sınıflandırılmıştır. Kalıplanmış numunelerin yoğunluk değerleri Çizelge 1'de verilmiştir. 16 adet kullanılan numune için ortalama yoğunluk değeri $1.73 \mathrm{gr} / \mathrm{cm}^{3}$ olarak belirlenmiş ve yoğunluk değerlerinin standart sapması $0.06 \mathrm{gr} / \mathrm{cm}^{3}$ olarak hesaplanmıştır. Yoğunluk değerlerindeki benzerlik dikkate alındığında numunelerin yakın boşluk oranı değerlerine sahip olmasının elde edilen sonuçların kıyaslanması açısından uygun olduğu kanaatine varılmıştır. Gerilme rahatlaması deneylerinden elde edilen zamana bağlı gerilme değerlerindeki azalma verisi Çizelge 2'de verilmiş ve Şekil 6-8'de grafiksel olarak gösterilmiştir (G1 kodlu numunelerde gerilme rahatlaması yoktur). Bulgulara göre, gerilme rahatlaması ile yaşanan gerilme değerlerindeki düşme hızı zaman ilerledikçe 
azalmaktadır. Numuneler için gerilme değerlerindeki azalmanın \% 50'lik kısmı 60 saniye içerisinde gerçekleşmiş ve numuneler 40 dakika içerisinde gerilme rahatlamalarını tamamlamış, ölçülen yük değerleri bu süre sonunda sıfırlanmıştır. Gerilme düşüşünün tamamlanması için geçen sürenin gerilme rahatlamasının başladığı gerilme $\left(\sigma_{i}\right)$ ve dolayısı ile birim deformasyon seviyesi arttıkça uzadığı görülmüştür. Çizelge 1'de verildiği üzere $\sigma_{i}$ değerlerinin tek eksenli sıkışma dayanımı (TESD) testi sonuçları üzerinde etkisi olduğu belirlenmiştir. Bir eşik seviyeye kadar $\sigma_{i}$ değerlerindeki artış neticesinde gerilme rahatlamasının TESD değerlerinde artış sağladığı, ancak rahatlamanın dayanım değerlerine yakın yüksek gerilme seviyesinde başlaması durumunun TESD değerleri üzerinde olumsuz etkisi olduğu görülmüştür (Şekil 9).
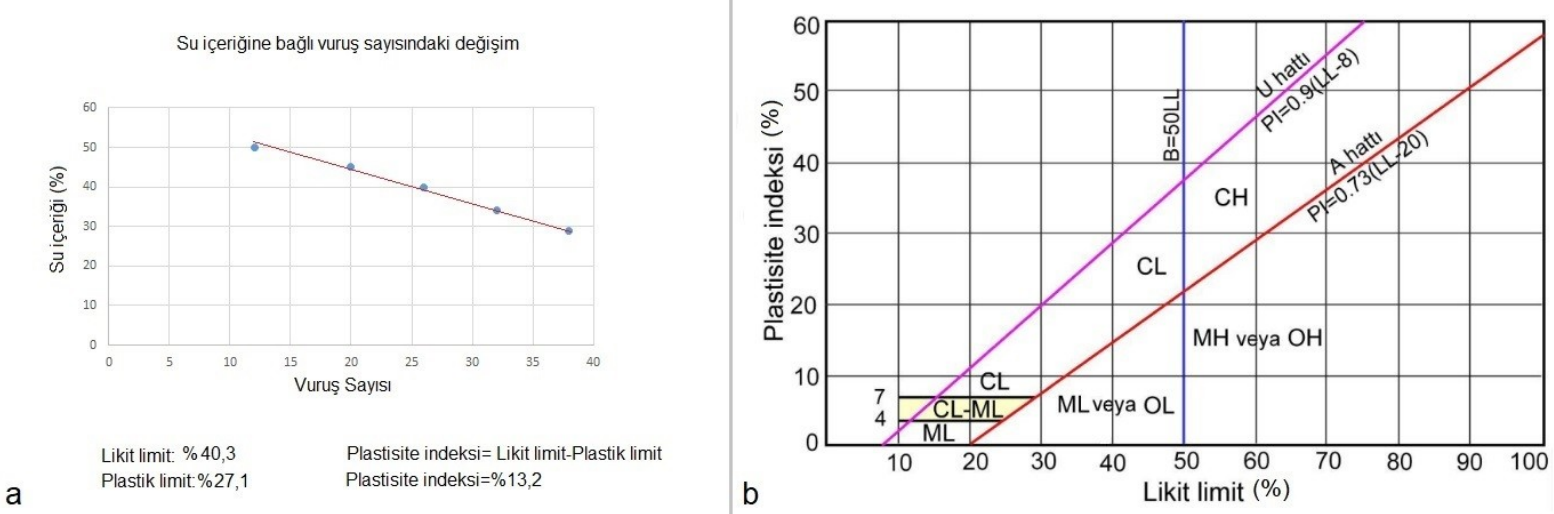

Şekil 5. a) Likit limit deneyinden elde edilen su içeriği ve vuruş sayısı değerleri, b) Casagrande plastisite kartı.

Figure 5. Blow numbers and water content data obtained from the liquid limit test, b) the Casagrande plasticity chart.

Çizelge 1. Rahatlama başlangıcındaki gerilme $\left(\sigma_{i}\right)$ değerleri, gerilme rahatlaması deneyi öncesi numunelerin yoğunlukları $(\rho)$ ve tek eksenli sıkışma dayanımı (TESD) deneyi sonuçları (NS: numune sayısı, SS: standart sapma).

Table 1. Stress level at the initiation of the relaxation $\left(\sigma_{i}\right)$ values, densities of specimens $(\rho)$ before the relaxation and uniaxial compressive strength (UCS) test results (NS: specimen number, SS: standard deviation).

\begin{tabular}{cccccccc}
\hline Grup & NS & $\begin{array}{c}\sigma_{\mathrm{i}} \\
(\mathrm{kPa})\end{array}$ & $\begin{array}{c}\sigma_{\mathrm{i}} \text { için SS } \\
(\mathrm{kPa})\end{array}$ & $\begin{array}{c}\rho \\
\left(\mathrm{gr} / \mathrm{cm}^{3}\right)\end{array}$ & $\begin{array}{c}\rho \text { için SS } \\
\left(\mathrm{gr} / \mathrm{cm}^{3}\right)\end{array}$ & $\begin{array}{c}\text { TESD } \\
(\mathrm{kPa})\end{array}$ & $\begin{array}{c}\text { TESD için } \\
\mathrm{SS}(\mathrm{kPa})\end{array}$ \\
\hline $\mathrm{G} 1$ & 4 & 0 & 0 & 1.72 & 0.06 & 97 & 5 \\
$\mathrm{G} 2$ & 4 & 34 & 3 & 1.75 & 0.07 & 115 & 7 \\
$\mathrm{G} 3$ & 4 & 60 & 4 & 1.70 & 0.05 & 131 & 6 \\
$\mathrm{G} 4$ & 4 & 86 & 3 & 1.76 & 0.06 & 104 & 8 \\
\hline
\end{tabular}


Çizelge 2. Farklı rahatlama sürelerinde gerilme $(\sigma)$ değerleri değişimi.

Table 2. Stress $(\sigma)$ variations for different relaxation times.

\begin{tabular}{cccccccccc}
\hline $\begin{array}{c}\text { Numune } \\
\text { (Grup) }\end{array}$ & $\begin{array}{c}\sigma_{\mathrm{i}} \\
(\mathrm{kPa})\end{array}$ & $\begin{array}{c}10 . \mathrm{sn} \\
\sigma(\mathrm{kPa})\end{array}$ & $\begin{array}{c}60 . \mathrm{sn} \\
\sigma(\mathrm{kPa})\end{array}$ & $\begin{array}{c}150 . \mathrm{sn} \\
\sigma(\mathrm{kPa})\end{array}$ & $\begin{array}{c}5 . \mathrm{dk} \\
\sigma(\mathrm{kPa})\end{array}$ & $\begin{array}{c}10 . \mathrm{dk} \\
\sigma(\mathrm{kPa})\end{array}$ & $\begin{array}{c}20 . \mathrm{dk} \\
\sigma(\mathrm{kPa})\end{array}$ & $\begin{array}{c}30 . \mathrm{dk} \\
\sigma(\mathrm{kPa})\end{array}$ & $\begin{array}{c}40 . \mathrm{dk} \\
\sigma(\mathrm{kPa})\end{array}$ \\
\hline $1(\mathrm{G} 2)$ & 35 & 23 & 14 & 9 & 4 & 1 & 0 & - & - \\
$2(\mathrm{G} 2)$ & 37 & 23 & 15 & 9 & 5 & 2 & 0 & - & - \\
$3(\mathrm{G} 2)$ & 30 & 19 & 13 & 8 & 4 & 2 & 0 & - & - \\
$4(\mathrm{G} 2)$ & 33 & 20 & 13 & 7 & 3 & 1 & 0 & - & - \\
$1(\mathrm{G} 3)$ & 62 & 39 & 24 & 17 & 11 & 6 & 2 & 0 & - \\
$2(\mathrm{G} 3)$ & 64 & 40 & 25 & 17 & 10 & 5 & 1 & 0 & - \\
$3(\mathrm{G} 3)$ & 59 & 39 & 23 & 15 & 10 & 4 & 2 & 0 & - \\
$4(\mathrm{G} 3)$ & 56 & 37 & 22 & 14 & 9 & 4 & 1 & 0 & - \\
$1(\mathrm{G} 4)$ & 88 & 64 & 45 & 34 & 23 & 14 & 6 & 3 & 0 \\
$2(\mathrm{G} 4)$ & 82 & 60 & 41 & 30 & 18 & 10 & 4 & 1 & 0 \\
$3(\mathrm{G} 4)$ & 85 & 61 & 42 & 28 & 17 & 9 & 3 & 1 & 0 \\
$4(\mathrm{G} 4)$ & 89 & 63 & 44 & 32 & 19 & 11 & 5 & 2 & 0 \\
\hline
\end{tabular}
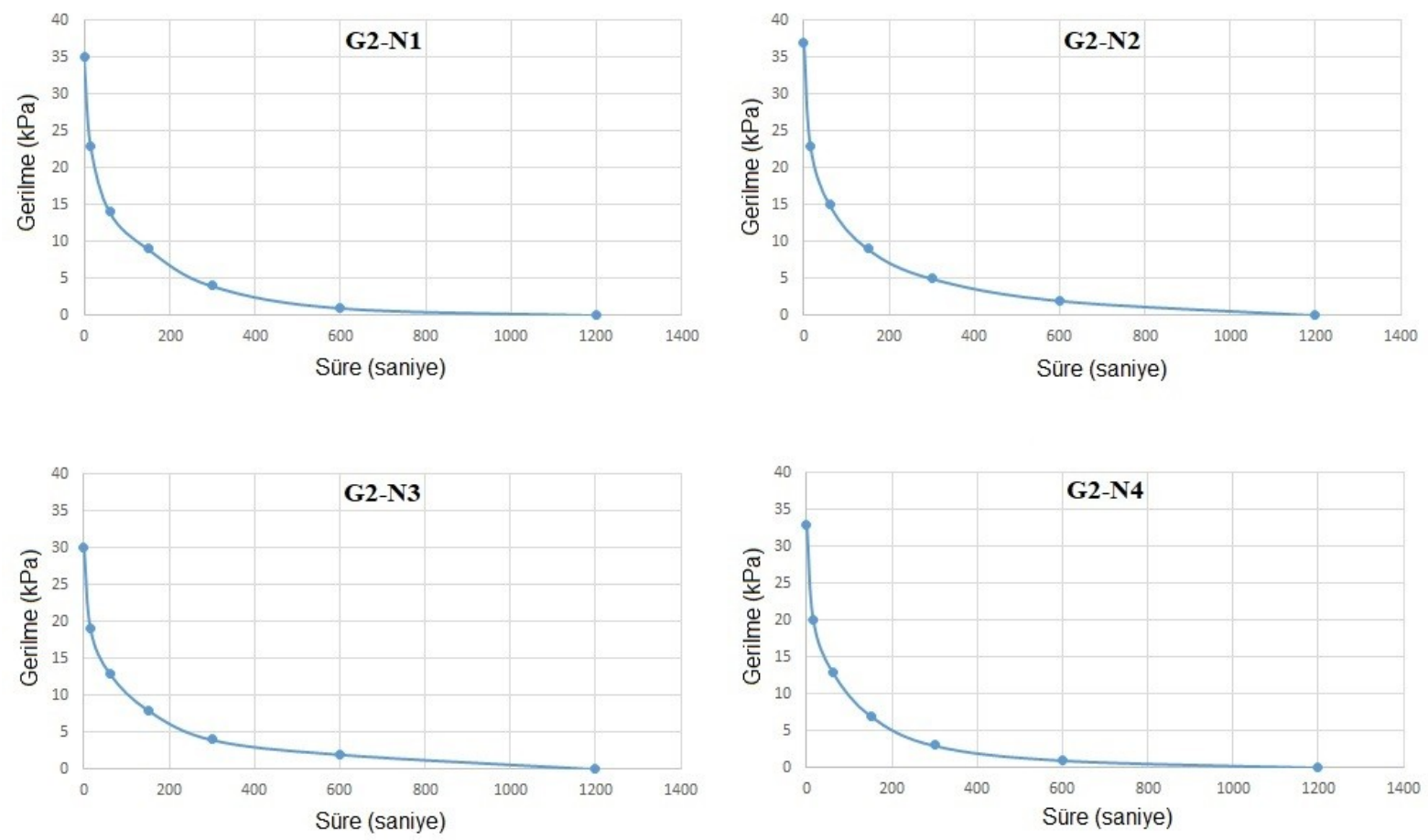

Şekil 6. G2 grubundaki numunelerin gerilme rahatlaması verileri ( $\mathrm{N}$ : numune numarası, G: Grup numarası).

Figure 6. Stress relaxation data for specimens in G2 group (N: specimen number, G: Group number). 

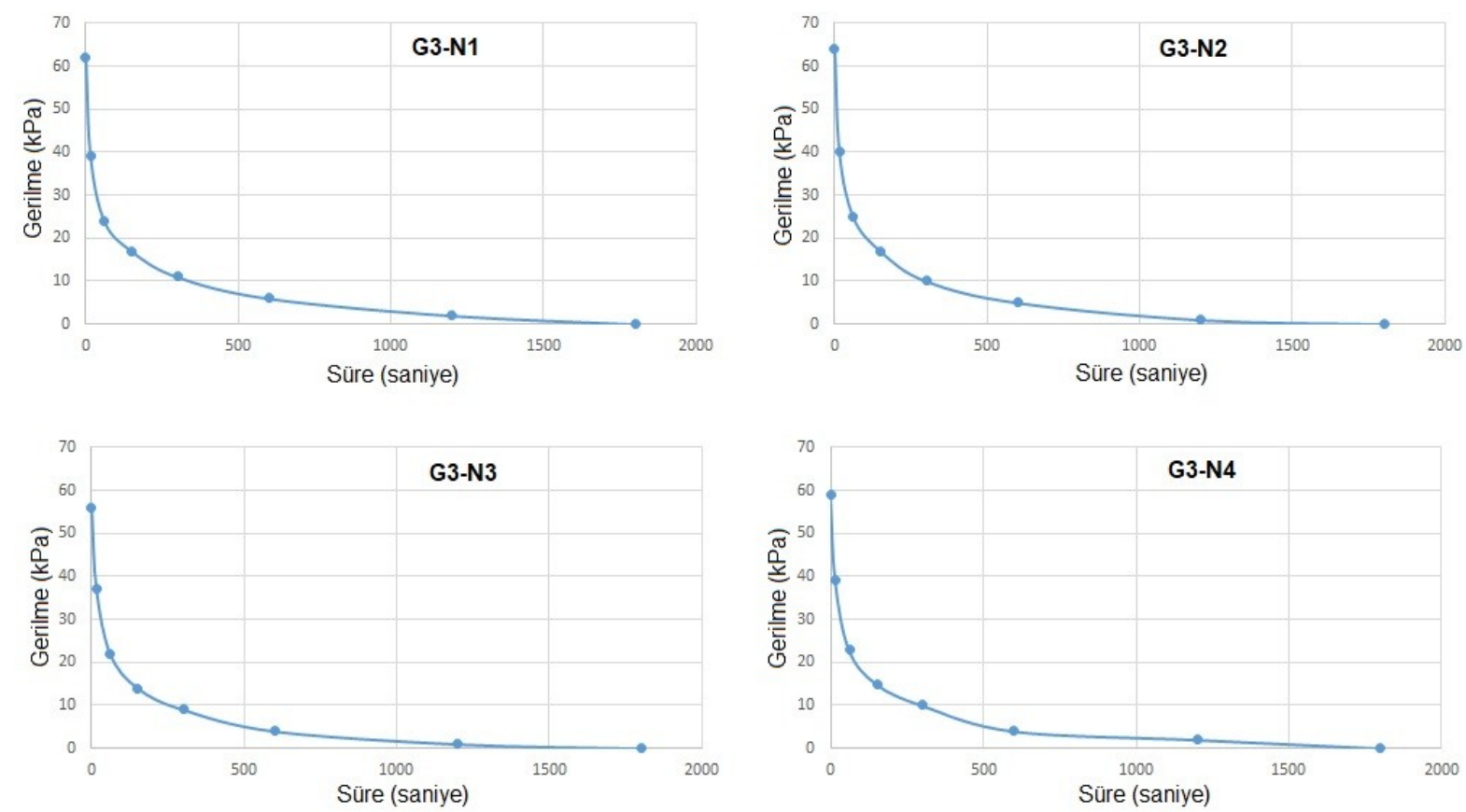

Şekil 7. G3 grubundaki numunelerin gerilme rahatlaması verileri ( $\mathrm{N}$ : numune numarası, G: Grup numarası).

Figure 7. Stress relaxation data for specimens in G3 group (N: specimen number, G: Group number).
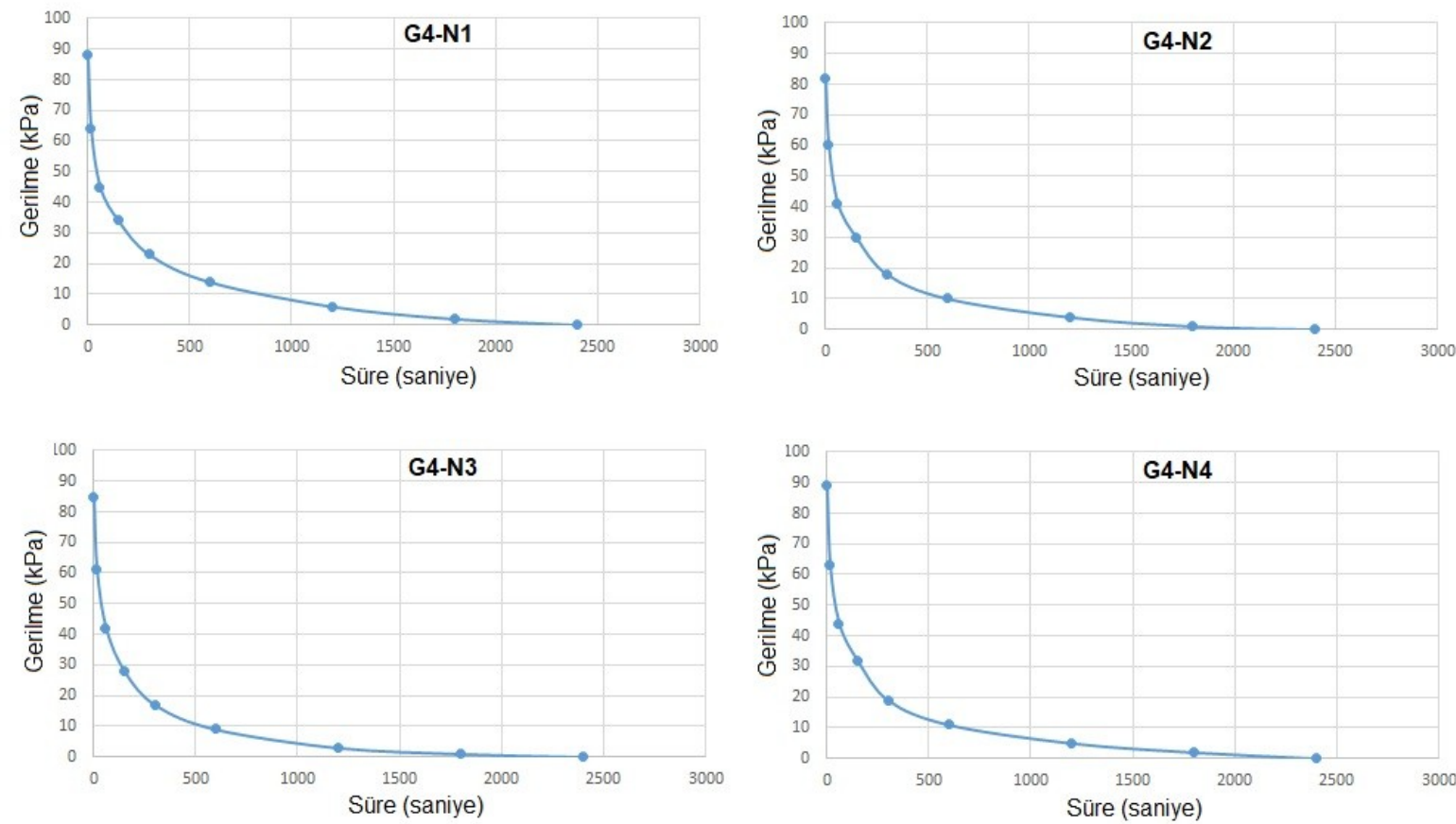

Şekil 8. G4 grubundaki numunelerin gerilme rahatlaması verileri ( $\mathrm{N}$ : numune numarası, G: Grup numarası).

Figure 8. Stress relaxation data for specimens in G4 group (N: specimen number, G: Group number). 


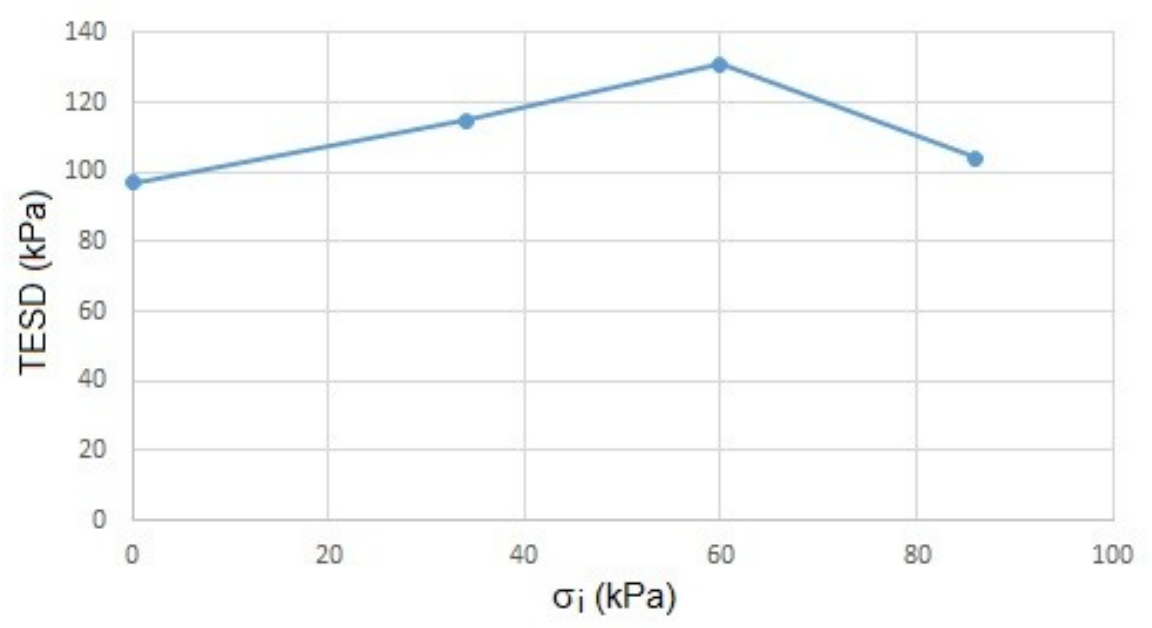

Şekil 9. Farklı $\sigma_{i}$ değerleri için tek eksenli sıkışma dayanımı (TESD) deneyi sonuçları.

Figure 9. Uniaxial Compressive strength (UCS) test results for various $\sigma_{i}$ values.

\section{TARTIŞMA}

Gerilme rahatlaması tamamlanana kadar farklı $\sigma_{i}$ seviyesi koşulları için gerilme değerlerindeki düşüş ölçülmüştür. Elde edilen önemli bulgulardan biri $\sigma_{i}$ değerlerindeki artış ile birlikte gerilme rahatlamasının tamamlanması için geçen sürenin uzamış olmasıdır. Bir diğer ifadeyle gerilme rahatlaması yaşanan birim deformasyon seviyesi arttıkça gerilme değerlerindeki azalmanın tamamlanması için daha uzun süre geçmektedir. Dış yükleme kaynaklı birim deformasyona uğrayan malzeme üzerindeki enerjinin zamana bağlı plastikleşmeye yol açması sonucu gerilme rahatlaması oluşmaktadır. Birim deformasyon ve enerji seviyesinde artış neticesinde gerilme rahatlaması esnasında geçen sürenin artacağı ilgili diğer çalışma sonuçları ile de doğrulanmıştır (Lade and Karimpour, 2016; Li et al., 2013).

Gerilme rahatlamasının özellikle ilk başladığı zamanlarda çok hızlı olduğu, gerilme değerlerindeki düşüşün önemli bir kısmın ilk dakika içerisinde gerçekleştiği ve tamamlanması için 40 dakikalık bir sürenin yeterli olduğu belirlenmiştir. Bu çalışmaya paralel olarak literatürdeki diğer ilgili çalışmalardan elde edilen bulgular da gerilme değerlerindeki düşüş hızının zaman ile azaldığı yönündedir (Bagheri et al., 2019; Augustesen et al., 2004; Tong and Yin, 2013).

Numunelerin belirli bir birim deformasyon seviyesine kadar yüklenmesi sebebi ile boşluk oranlarında azalma olması ve kompaksiyon gerçekleşmesi nedeniyle gerilme 
rahatlaması sonucunda dayanım değerlerinde artış olması tahmin edilebilir bir neticedir. Ancak çok yüksek $\sigma_{i}$ değerlerinin dayanım değerlerinde düşüşe sebebiyet verebileceği görülmüştür. Yüksek birim deformasyonlar zemin içerisinde mikro-makro çatlak başlangıçlarına sebep olduğu için dayanım değerlerine yaklaşan $\sigma_{i}$ seviyelerinde gerçekleşen gerilme rahatlaması zemin dayanımını olumsuz yönde etkileyebilecektir (Dijkstra et al., 2019; Komurlu and Kesimal, 2015; Hanley et al., 2015).

Kompaksiyon zeminlerin elastisite modulü gibi deformabilite özellikleri üzerinde de etkin bir role sahiptir. Tane temas koşulları ve boşluk oranı birim deformasyon seviyesine bağlı olarak önemli ölçüde değişebilmektedir. Literatürdeki ilgili çalışmalarda gerilme rahatlaması sonucunda zeminlerin elastisite modulü değerlerinde artış olduğu belirlenmiştir (Miksic and Alava, 2013; Sheahan et al., 1994; Chegenizadeh et al., 2020).

Zemin tabakası kalınlığı süre ile alakalı özellikler açısından belirleyici parametreler arasındadır. Gerilme rahatlamasının numune boyutunun büyümesi durumunda daha uzun sürmekte olduğu bu konuda literatürde rapor edilmiştir (Bock et al., 1991; Xu et al., 2018). Bu sebeple arazi ölçeğinde gerilme rahatlamasının laboratuvar ölçeğine kıyasla daha uzun süreceği öngörülebilmektedir.

\section{SONUÇ}

Bu çalışmada gerilme rahatlamasının silt türü bir zeminin TESD değerleri üzerindeki etkileri bir dizi deneysel çalışma ile incelenmiştir. Çoğu mühendislik tasarım ve analizlerinde ihmal ediliyor olsa da gerilme rahatlamasının zemin dayanım değerleri üzerinde önemli etkiye sahip olduğu belirlenmiştir. Gerilme rahatlamasının gerçekleştiği birim deformasyon seviyesine bağlı olarak TESD değerleri önemli ölçüde artış gösterebilmektedir. Gerilme rahatlaması hızının zamanla azaldığı ve birim deformasyon seviyesi arttıkça gerilme rahatlamasının tamamlanması için geçen sürenin uzadığı elde edilen diğer önemli çıktılardır. Bu çalışmanın gerilme rahatlaması sebebiyle zemin dayanım değerlerindeki değişimlerin daha iyi anlaşılmasına katkı sağlayacağı düşünülmektedir. Literatürde kısıtlı sayıda çalışma olduğundan zeminlerin dayanım ve diğer çeşitli özellikleri üzerindeki etkileri ile ilgili 
ilerleyen analizler için gerilme rahatlaması konusunda yeni araştırmalar fayda sağlayacaktır.

\section{KAYNAKLAR}

ASTM International, 2010. ASTM D4318-10: Standard Test Methods for Liquid Limit, Plastic Limit, and Plasticity Index of Soils. 2010 Annual Book of ASTM Standards, ASTM International, West Conshohocken, PA

Augustesen, A., Liingaard, M. and Lade P.V., 2004. Evaluation of Time-Dependent Behavior of Soils. International Journal of Geomechanics, 4(3), 137-156.

Bagheri, M., Rezania, M. and Nezhad, M.M., 2019. Rate Dependency and Stress Relaxation of Unsaturated Clays. International Journal of Geomechanics, 19(12), 04019128.

Bock, R.G., Puri, V.M. and Manbeck, H.B., 1991. Triaxial test sample size effect on stress relaxation of wheat en masse. Transactions of the ASAE, 34(3), 966-971.

Chegenizadeh, A., Keramatikerman, M., Nikraz, H., 2020. Effect of loading strain rate on creep and stress-relaxation characteristics of sandy silt. Results in Engineering, 7, 100143.

Dijkstra, J., Andò, E. and Dano, C., 2019. Grain kinematics during stress relaxation in sand: not a problem for X-ray imaging. E3S Web of Conferences, 92, 01001.

Dob, H., Messast, S., Boulon, M. and Flavigny, E., 2016. Treatment of the High Number of Cycles as a Pseudo-Cyclic Creep by Analogy with the Soft Soil Creep Model. Geotechnical and Geological Engineering, 34, 1985-1993.

Hanley, K.J., O'Sullivan, C., Wadee, M.A. and Huang, X., 2015. Use of elastic stability analysis to explain the stress-dependent nature of soil strength. Royal Society Open Science, 2(4), 150038.

Kamao, S., 2016. Creep And Relaxation Behavior of Highly Organic Soil. International Journal of Geomate, 11(25), 2506-2511

Komurlu, E. and Kesimal, A., 2015. Experimental study of polyurethane foam reinforced soil used as a rock-like material. Journal of Rock Mechanics and Geotechnical Engineering, 7(5), 566-572.

Kutergin, V.N., Kalbergenov, R.G., Karpenko, F.S., Leonov, A.R. and Merzlyakov, V.P., 2013. Determination of Rheological Properties of Clayey Soils by the Relaxation Method. Soil Mechanics and Foundation Engineering, 50, 1-6.

Kwok, C.Y. and Bolton, M.D., 2013. DEM simulations of soil creep due to particle crushing. Géotechnique, 63(16), 1365-1376. 
Lade, P.V., Nam, J. and Liggio, C.D.J., 2010. Effects of Particle Crushing in Stress Drop-Relaxation Experiments on Crushed Coral Sand. Journal of Geotechnical and Geoenvironmental Engineering, 136(3), 500-509.

Lade, P.V. and Karimpour, H., 2015. Stress relaxation behavior in Virginia Beach sand. Canadian Geotechnical Journal, 52(7), 813-835.

Lade, P.V. and Karimpour, H., 2016. Stress drop effects in time dependent behavior of quartz sand. International Journal of Solids and Structures, 87(1), 167-182.

Levin, F., Vogt, S. and Cudmani, R., 2019. Time-dependent behaviour of sand with different fine contents under oedometric loading. Canadian Geotechnical Journal, 56(1), 102-115.

Li, G., Ni, C., Pei, H., Wan-ming, G. and Ng, C.W.W., 2013. Stress relaxation of grouted entirely large diameter B-GFRP soil nail. China Ocean Engineering, 27, 495-508.

Liingaard, M., Augustesen, A. and Lade, P.V., 2004. Characterization of Models for Time-Dependent Behavior of Soils. International Journal of Geomechanics, $4(3), 157-177$.

Miksic, A. and Alava, M.C., 2013. Evolution of grain contacts in a granular sample under creep and stress relaxation. Physical Review E, 88, 032207.

Sabir, M.A., Umar, M., Farooq, M. and Faridullah, F., 2016. Computing soil creep velocity using dendrochronology. Bulletin of Engineering Geology and the Environment, 75, 1761-1768.

Sanchez-Giron, V., Andreu, E. and Hernanz, J.L., 2001. Stress relaxation of five different soil samples when uniaxially compacted at different water contents. Soil and Tillage Research, 62(3-4), 85-99.

Sheahan, T., Ladd, C. and Germaine, J., 1994. Time-Dependent Triaxial Relaxation Behavior of a Resedimented Clay. Geotechnical Testing Journal, 17(4), 444452.

Staszewska, K. and Cudny, M., 2020. Modelling the time-dependent behaviour of soft soils. Studia Geotechnica et Mechanica, 42(2), 97-110.

Tong, F. and Yin, J.H., 2013. Experimental and Constitutive Modeling of Relaxation Behaviors of Three Clayey Soils. Journal of Geotechnical and Geoenvironmental Engineering, 139(11), 1973-1981.

Tran, T.T.T., Hazarika, H., Indrawan, I.G.B. and Karnawati, D., 2018. Prediction of Time to Soil Failure Based on Creep Strength Reduction Approach. Geotechnical and Geological Engineering, 36, 2749-2760. 
Wang, Y.F., Zhou, Z.G. and Cai, Z.Y., 2014. Studies about Creep Characteristic of Silty Clay on Triaxial Drained Creep Test. Applied Mechanics and Materials, 580-583, 355-358.

Xu, M., Hong, J. and Song, E., 2018. DEM study on the macro- and micro-responses of granular materials subjected to creep and stress relaxation. Computers and Geotechnics, 102, 111-124.

Yin, Z.Y., Zhu, Q.Y., Yin, J.H. and Ni, Q., 2014. Stress relaxation coefficient and formulation for soft soils. Geotechnique Letters, 4(1), 45-51. 